\title{
CD11c $^{+} /$CD11b $^{+}$Cells Are Critical for Organic Dust-Elicited Murine Lung Inflammation
}

\author{
Jill A. Poole1, Angela M. Gleason'1, Christopher Bauer¹, William W. West ${ }^{2}$, Neil Alexis ${ }^{3}$, \\ Nico van Rooijen ${ }^{4}$, Stephen J. Reynolds5, Debra J. Romberger ${ }^{1,6}$, and Tammy L. Kielian ${ }^{2}$ \\ ${ }^{1}$ Pulmonary, Critical Care, Sleep, and Allergy Division, Department of Medicine, and ${ }^{2}$ Department of Pathology and Microbiology, University of \\ Nebraska Medical Center, Omaha, Nebraska; ${ }^{3}$ Center for Environmental Medicine, Asthma, and Lung Biology, University of North Carolina School \\ of Medicine, Chapel Hill, North Carolina; ${ }^{4}$ Department of Molecular Cell Biology, Vrije University, Amsterdam, The Netherlands; ${ }^{5}$ High Plains \\ Intermountain Center for Agricultural Health and Safety, Department of Environmental and Radiological Health Sciences, Colorado State University, \\ Fort Collins, Colorado; and ${ }^{6}$ Veterans Administration-Nebraska Western lowa Healthcare System, Omaha, Nebraska
}

Organic dust exposure in the agricultural industry results in significant lung disease. Macrophage infiltrates are increased in the lungs after organic dust exposures, yet the phenotype and functional importance of these cells remain unclear. Using an established intranasal inhalation murine model of dust-induced lung inflammation, animals were treated once or daily for 3 weeks with swine confinement organic dust extract (DE). Repetitive DE treatment

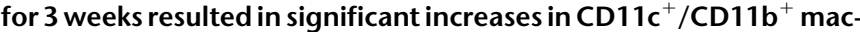
rophages in whole lung-associated tissue. These cells displayed increased costimulatory molecule (CD80 and CD86) expression, enhanced phagocytic ability, and an increased production of IL-6, CXCL1, and CXCL2. Similar findings were observed with the $\mathrm{CD} 1 \mathrm{c}^{+} / \mathrm{CD} 11 \mathrm{~b}^{+}$macrophage infiltrate after repetitive exposure to peptidoglycan, a major DE component. To determine the functional importance of macrophages in mediating DE-induced airway inflammation, lung macrophages were selectively depleted using a well-established intranasal clodronate liposome depletion/suicide strategy. First, macrophage depletion by clodronate liposomes resulted in significant reductions in airway neutrophil influx and TNF- $\alpha$ and IL- 6 production after a single exposure to DE. In contrast, after repetitive 3-week exposure to $D E$, airway lavage fluid and lung tissue neutrophils were significantly increased in clodronate liposome-treated mice compared with control mice. A histological examination of lung tissue demonstrated striking increases in alveolar and bronchiolar inflammation, as well as in the size and distribution of cellular aggregates in clodronate-liposome versus saline-liposome groups repetitively exposed to $\mathrm{DE}$. These studies demonstrate that

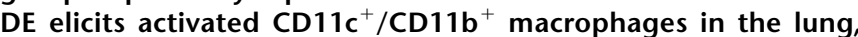
which play a critical role in regulating the outcome of $\mathrm{DE}$-induced airway inflammation.

Keywords: macrophage; neutrophil; airway inflammation; peptidoglycan; organic dust

The chronic inhalation of organic dusts or bioaerosols can result in several respiratory diseases including chronic bronchitis, asthma, and obstructive lung disease $(1,2)$. Agricultural workers

(Received in original form March 7, 2012 and in final form July 10, 2012)

This work was supported by grants R01 ES019325, K08 ES015522-01, and the American Recovery \& Reinvestment Act (ARRA) ES015522-03S1 from the National Institute of Environmental Health Sciences (J.A.P.), grants 1R01OH008539-01 (D.J.R.) and $5 \mathrm{U} 50 \mathrm{OH} 0080856$ (S.J.R.) from the National Institute of Occupationa Safety Health, and grant 2R01NS055385 from the National Institute of Neurological Disorders and Stroke (T.L.K.).

Correspondence and requests for reprints should be addressed to Jill A. Poole, M.D., Pulmonary, Critical Care, Sleep, and Allergy Division, Department of Medicine, University of Nebraska Medical Center, 985300 The Nebraska Medical Center, Omaha, NE 68198-5300. E-mail: japoole@unmc.edu

This article has an online supplement, which is accessible from this issue's table of contents at www.atsjournals.org

Am J Respir Cell Mol Biol Vol 47, Iss. 5, pp 652-659, Nov 2012

Copyright $\odot 2012$ by the American Thoracic Society

Originally Published in Press as DOI: 10.1165/rcmb.2012-0095OC on July 19, 2012

Internet address: www.atsjournals.org

\section{CLINICAL RELEVANCE}

Inhalation exposure to organic dust extract from swine confinement facilities induces an influx of activated CD11 $\mathrm{c}^{+} /$ $\mathrm{CD}_{11} \mathrm{~b}^{+}$macrophages in the lung. Our findings established lung macrophages as key to the acute response to dust extract, and furthermore, lung macrophages are critical in down-regulating inflammatory responses after prolonged, repetitive dust extract exposures. This information may be important because potential therapies such as macrolides and vitamin $\mathrm{D}$ were shown to enhance macrophage phagocytic ability or autophagy.

are routinely exposed to organic dust environments, with the highest prevalence of airway disease associated with animal farming exposures, particularly swine confinement operations (2). Initial exposure to organic dust induces an intense proinflammatory response marked by fevers, bronchial hyperresponsiveness, and increases in bronchoalveolar lavage fluid (BALF) inflammatory cells and cytokines/chemokines that wane over time. However, persons chronically exposed to these environments are at increased risk of lung function decline, airway inflammation, and progressive respiratory impairment (1, 3-5). Although this paradigm, termed "chronic adaptation inflammatory response" (1), has been replicated and described in animal models by our group (6) and others (7), the critical cellular mechanisms underlying this response remain unclear.

Lung mononuclear phagocytes and macrophages are important innate immune lung effectors that serve a critical role in host defense against inhaled environmental insults and toxins (8-10). These cells can orchestrate inflammatory responses through the release of mediators that promote inflammation, activate epithelial cells, and elicit neutrophil recruitment $(11,12)$. Macrophages produce several mediators after in vitro exposure to organic dust extract (DE) that are associated with agriculturally induced disease, such as TNF- $\alpha$, IL-6, and CXCL8 $(1,13)$. In the lung, alveolar macrophages are well recognized to represent the largest mononuclear phagocyte population (14). These cells differ from other tissue macrophages based on their high expression levels of CD11c, which is a molecule typically not present on other tissue macrophages, and is generally considered a dendritic cell marker (15-20). Furthermore, CD11b expression, which is high in other tissue macrophage populations, is quite low in alveolar macrophages, unless these cells are activated $(16,17)$. Lifetime nonsmoking swine farmers demonstrate signs of bronchial inflammation with neutrophils, alveolar macrophages, and lymphocytes present in lavage fluid (21). Furthermore, evidence suggests that the alveolar macrophages in these farmers may be activated, based on observations of increased 
macrophage chemotactic activity and ex vivo oxygen radical formation (21). Airway and lung parenchymal macrophage infiltrates are also increased in mice after organic dust exposure (6, 7). However, the phenotype and functional importance of these cells have not been well described. Therefore, to address the functional role of alveolar macrophages in the context of repetitive DE-induced lung inflammation, we analyzed CD11 ${ }^{+}$lung macrophages to determine their activation phenotype. In addition, we compared these responses with those of peptidoglycan (PGN), a major component of organic DE previously shown to drive DE-elicited inflammatory responses in macrophages (13). Finally, we selectively depleted lung macrophages using a wellestablished intranasal clodronate liposome macrophage depletion/ suicide strategy to determine the functional importance of these cells in the context of both single and repetitive DE exposures $(17,22,23)$.

Our studies demonstrate that both DE and PGN exposure elicited increased numbers of activated CD $11 \mathrm{c}^{+} / \mathrm{CD} 11 \mathrm{~b}^{+}$lung macrophages that were critical for regulating the extent of inflammation. Namely, airway inflammatory responses were attenuated after a one-time exposure to DE. However, after repetitive DE exposures, lung inflammatory and pathologic outcomes, primarily marked by neutrophil influx, were significantly worse when macrophages were depleted. Collectively, these studies demonstrate a critical role for lung macrophages in controlling DE-induced lung inflammation.

\section{MATERIALS AND METHODS}

\section{Organic DE}

DE was prepared as previously described $(24,25)$, with details provided in the online supplement.

\section{Animal Model}

Using an established intranasal instillation murine model of organic dust-induced and PGN-induced airway inflammation (6), C57BL/6 mice (6-8 wk old; Jackson Laboratory, Bar Harbor, ME) were treated once (acute/single exposure) or daily for 3 weeks (repetitive exposure) with $12.5 \%$ DE, PGN $(100 \mu \mathrm{g})$, or sterile PBS (diluent). The Staphylococcus aureus PGN (Sigma, St. Louis, MO) concentration comprises approximately half the protein in $12.5 \% \mathrm{DE}$, and elicits airway inflammatory responses similar to those of DE (26). Whole lung cells were isolated, as described previously (27) and in the online supplement. All animal experimental procedures were approved by the Institutional Animal Care and Use Committee of the University of Nebraska Medical Center, according to National Institutes of Health guidelines for the use of rodents.

\section{Macrophage Depletion}

The intranasal delivery of encapsulated clodronate liposomes is a wellestablished method to deplete lung macrophages selectively $(17,18,28)$. Liposomes $(30 \mu \mathrm{l})$ were administered 48 hours before the first DE treatment, and every 3-4 days throughout the 3-week repetitive DE period to maintain macrophage depletion.

\section{BALF}

BALF was collected as previously described (6). The total cell number of pooled lavages $(3 \times 1 \mathrm{ml}$ lavages $)$ was enumerated, and differential cell counts were determined on cytospin-prepared slides (Cytopro Cytocentrifuge; Wescor, Inc., Logan, UT) stained with Diff-Quik (Dade Behring, Newark, DE). Cell-free supernatants for cytokine analysis from the first lavage were collected and stored at $-20^{\circ} \mathrm{C}$.

\section{Lung Histology}

Whole lungs were inflated to $10 \mathrm{~cm} \mathrm{H}_{2} \mathrm{O}$ pressure with $10 \%$ formalin (Sigma) to preserve pulmonary architecture. Lungs were processed and embedded in paraffin, and sections $(4-5 \mu \mathrm{m})$ were cut and stained with hematoxylin and eosin. Slides were semiquantitatively assessed, using a previously described lung inflammatory scoring system $(6,26)$ by a pathologist (W.W.W.) blinded to the treatment conditions.

\section{Flow Cytometry}

Whole lung cells from each animal were incubated with anti-CD16/32 (Fc Block; BD Biosciences, San Jose, CA), and then stained with monoclonal antibodies directed against CD11c, CD11b, IA-b, CD80, CD86, Ly-6G, and appropriate isotype control samples (BD Biosciences). The CD11 ${ }^{+}$macrophage gating strategy is depicted in Figure E1 in the online supplement. The $\mathrm{CD} 11 \mathrm{c}^{+}$macrophage number was calculated by multiplying the percentage of gated cells measured by flow cytometry by the original hemocytometer count of total cells recovered for each animal.

\section{Phagocytosis Assay}

The phagocytic capacity of lung-associated $\mathrm{CD} 11 \mathrm{c}^{+}$cells was assessed by flow cytometry, modified from methods described previously (10, 13) and in the online supplement.

\section{Cytokine Assays}

CD $11 \mathrm{c}^{+}$lung cells isolated by FACS from mice repetitively exposed to saline and DE were analyzed for ex vivo cytokine/chemokine (e.g., TNF- $\alpha$, IL-6, KC/CXCL1, or MIP-2/CXCL2) responsiveness to subsequent DE restimulation by ELISA. Details are provided in the online supplement.

\section{Statistical Methods}

Data are presented as means \pm SEM. Statistical analyses were performed using a two-tailed, nonpaired $t$ test and one-way ANOVA with the Tukey multicomparison post hoc test. We used GraphPad (version 5.01; GraphPad Software, La Jolla, CA) software. In all analyses, $P$ values less than 0.05 were considered statistically significant.

\section{RESULTS}

\section{Organic Dust Exposure Induces the Accumulation of Activated CD11 ${ }^{+} / \mathrm{CD}_{11} \mathrm{~b}^{+}$Lung Macrophages}

The total number of lung-associated cells had increased after 3-week repetitive DE exposure compared with saline control samples, concomitant with significant elevations in the absolute number of $\mathrm{CD}_{11 \mathrm{c}^{+}}$cells (Figure 1A). The expression of costimulatory molecules (CD80 and CD86) and of the adhesion molecule CD11b was significantly up-regulated in lung-associated $\mathrm{CD}_{11 \mathrm{c}^{+}}$cells after DE challenge, compared with saline-treated control samples (Figure 1B). No change was observed in MHC Class II expression.

A significant increase was evident in the phagocytic ability of lung $\mathrm{CD} 11 \mathrm{c}^{+}$macrophages after repetitive DE challenge, compared with saline-treated mice (Figures $2 \mathrm{~A}$ and $2 \mathrm{~B}$ ). In addition, IL- 6 and CXCL1 production were significantly increased in ex vivo stimulated CD11 ${ }^{+}$macrophages obtained from DE-treated animals compared with saline-treated mice, whereas TNF- $\alpha$ was significantly decreased (Figure 2C). Interestingly, CD11 ${ }^{+}$cells from DE-treated mice produced elevated concentrations of IL-6, CXCL1, and CXCL2 at baseline, compared with saline-treated mice. Collectively, these data demonstrate that repetitive intranasal inhalation challenge with DE evokes a significant influx of CD11c ${ }^{+}$lung cells, demonstrating an activated phenotype as revealed by increased CD11b and costimulatory molecule expression, phagocytic ability, and selected cytokine responsiveness to subsequent DE exposure. 
A
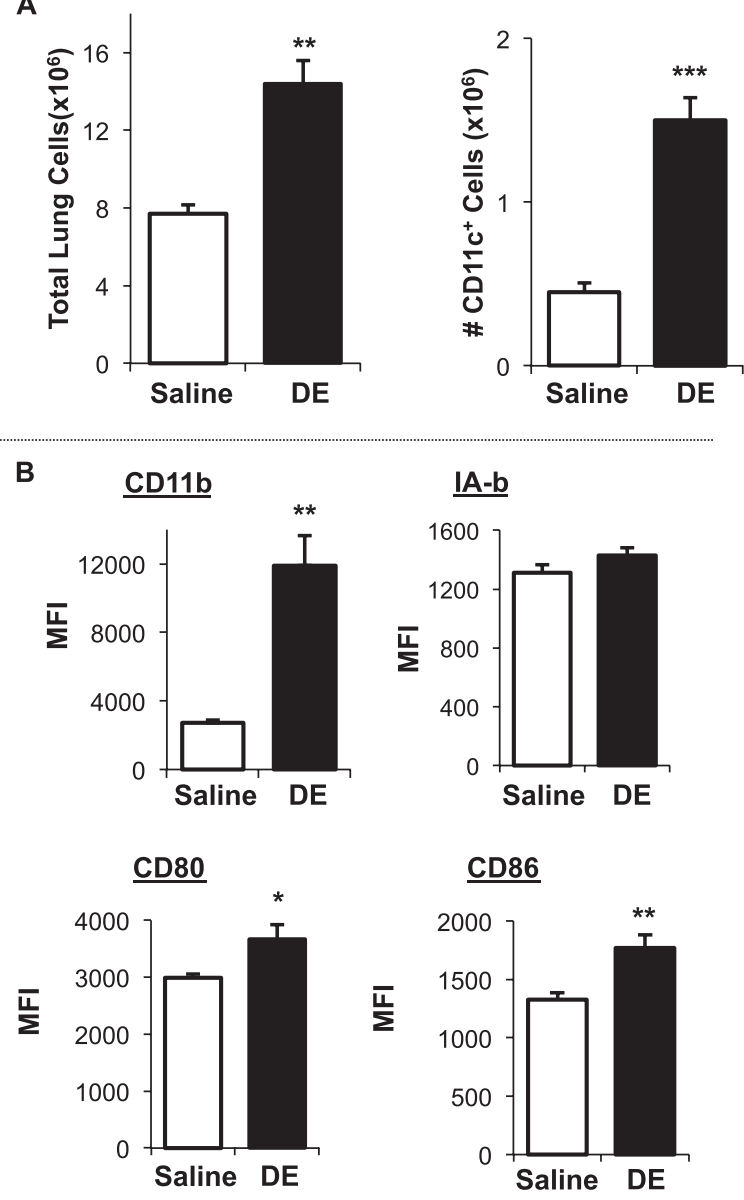

Figure 1. Repetitive organic dust extract (DE) exposure leads to the activation of $\mathrm{CD} 11 \mathrm{c}^{+}$lung macrophages. Lung-associated cells were collected from $\mathrm{C} 57 \mathrm{BL} / 6$ mice after 3 weeks of repetitive intranasal exposure to DE or saline control, and stained for FACS. $(A)$ Results represent total lung cells and absolute $\mathrm{CD} 11 \mathrm{c}^{+}$cells. \#, number of. (B) Mean fluorescence intensity (MFI) of surface marker expression on gated $\mathrm{CD}_{11 \mathrm{c}^{+}}$cells is shown. Results represent the mean $\pm \operatorname{SEM}(n=$ 6 mice/group), with statistical significance denoted by asterisks $\left({ }^{*} P<0.05,{ }^{* *} P<0.01\right.$, and $\left.{ }^{* * *} P<0.001\right)$.

\section{Repetitive Intranasal Challenge with PGN Induces Activated $\mathrm{CD} 11 \mathrm{c}^{+} / \mathrm{CD} 11 \mathrm{~b}^{+}$Macrophages}

Because emerging evidence suggests that bacterial PGNs in industrial animal farming environments are highly prevalent and may be responsible for mediating airway disease $(29,30)$, and because our previous work demonstrated that PGN exposureinduced outcomes closely resemble those elicited by DE exposure $(13,26)$, we investigated the effects of intranasal PGN inhalation in separate experiments. Similar to what was observed among DE-treated mice, PGN induced an expansion in total lung cell infiltrates, with an increase in total number of CD11 $\mathrm{c}^{+}$macrophages (Figure 3A). Repetitive PGN exposure resulted in increased costimulatory molecule expression (CD80 and CD86) and increased adhesion molecule CD11b expression (Figure 3B) in CD11 $\mathrm{c}^{+}$lung macrophages, consistent with the observations already described for DE. However, unlike treatment with DE, PGN treatment significantly augmented MHC Class II expression in CD11 ${ }^{+}$cells (Figure 3B). The phagocytic ability of lung CD11 ${ }^{+}$cells from PGN-challenged mice was also significantly enhanced compared with saline-treated mice (Figure 3B). Collectively, these results show that repetitive PGN treatment results in a significant influx of $\mathrm{CD}_{11 \mathrm{c}^{+}}$lung cells, demonstrating an activated phenotype, similar to findings observed after DE exposure.

\section{Effects of Lung Macrophage Depletion in Acute DE-Induced Airway Inflammation}

Next, we sought to assess the functional importance of lung macrophages in mediating DE-induced airway inflammation by selectively depleting these cells via the intranasal delivery of clodronate-encapsulated liposomes. To establish the efficacy and safety of this approach, we first investigated airway inflammatory outcomes in an acute DE-induced airway model (6). Clodronate liposomes (CL-LIP) and saline liposomes (SLLIP) were administered 2 days before a one-time (acute) exposure to DE or saline control, whereupon mice were killed 5 hours after DE exposure. Macrophage reduction was confirmed by a microscopic review of the hematoxylin and eosin staining of lung sections. Decreases in macrophage infiltrates $(>80 \%$ ) were observed in CL-LIP-treated mice, compared with SL-LIP-treated animals (Figure 4). Significant reductions in macrophage recovery $(>80 \%)$ from BALF in CL-LIP + saline and CL-LIP + DE animals were evident, compared with respective SL-LIP control mice (Figure 5A).

Macrophage reduction also produced changes in acute DEinduced airway inflammation. DE-induced airway neutrophil influx was nonsignificantly $(P=0.11)$ reduced in CL-LIP + DE-treated mice compared with SL-LIP + DE mice (Figure $5 \mathrm{~A})$. Significant decreases in TNF- $\alpha$ and IL-6 concentrations in CL-LIP + DE-treated animals were evident, compared with SL-LIP + DE-treated animals (Figure 5B). Interestingly, the expression of neutrophil chemokines was differently affected by macrophage infiltrates, because CXCL1 was significantly elevated in CL-LIP + DE-treated mice compared with SL-LIP + DE-treated mice, whereas CXCL2 concentrations were similar (Figure 5B). These studies demonstrate that macrophages play a selective role in regulating acute (single exposure) DE-induced airway inflammatory responses.

\section{Effects of Alveolar Macrophage Depletion in Repetitive DE-Induced Airway Inflammation}

Next, we investigated the role of macrophages in the repetitive exposure model to determine the functional importance of macrophages in mediating the chronic inflammatory adaptation-like response to DE. The administration of CL-LIP throughout the duration of repetitive DE exposure treatment (CL-LIP + DE) resulted in increased neutrophil numbers recovered from BALF, compared with SL-LIP + DE-treated animals (Figure 6A). As expected, macrophage recovery in BALF and whole-lung tissue was significantly reduced in CL-LIP + DE-treated mice compared with SL-LIP + DE-treated animals, confirming the efficacy of the clodronate liposome-mediated depletion approach (Figures 6A and 6B). CL-LIP did not alter the activation profiles of the few $\mathrm{CD} 11 \mathrm{c}^{+}$macrophages that were detected in the lungs after repetitive DE exposure, compared with SL-LIP-treated mice. Namely, CD11b, CD80, and CD86 expression had all increased (data not shown). The percentage and numbers of lung neutrophils from whole-lung tissue were significantly increased in animals treated with CL-LIP + DE, compared with SL-LIP + DE (Figure 6B). After 3 weeks of repetitive exposure, BALF cytokines and chemokines were at the lower limit of assay detection, consistent with the chronic inflammatory adaptation response $(6,7)$, and concentrations were not different between SL-LIP + DE and CL-LIP + DE (data not shown).

The histological examination of lung tissue demonstrated striking differences in lung parenchymal inflammation between the 


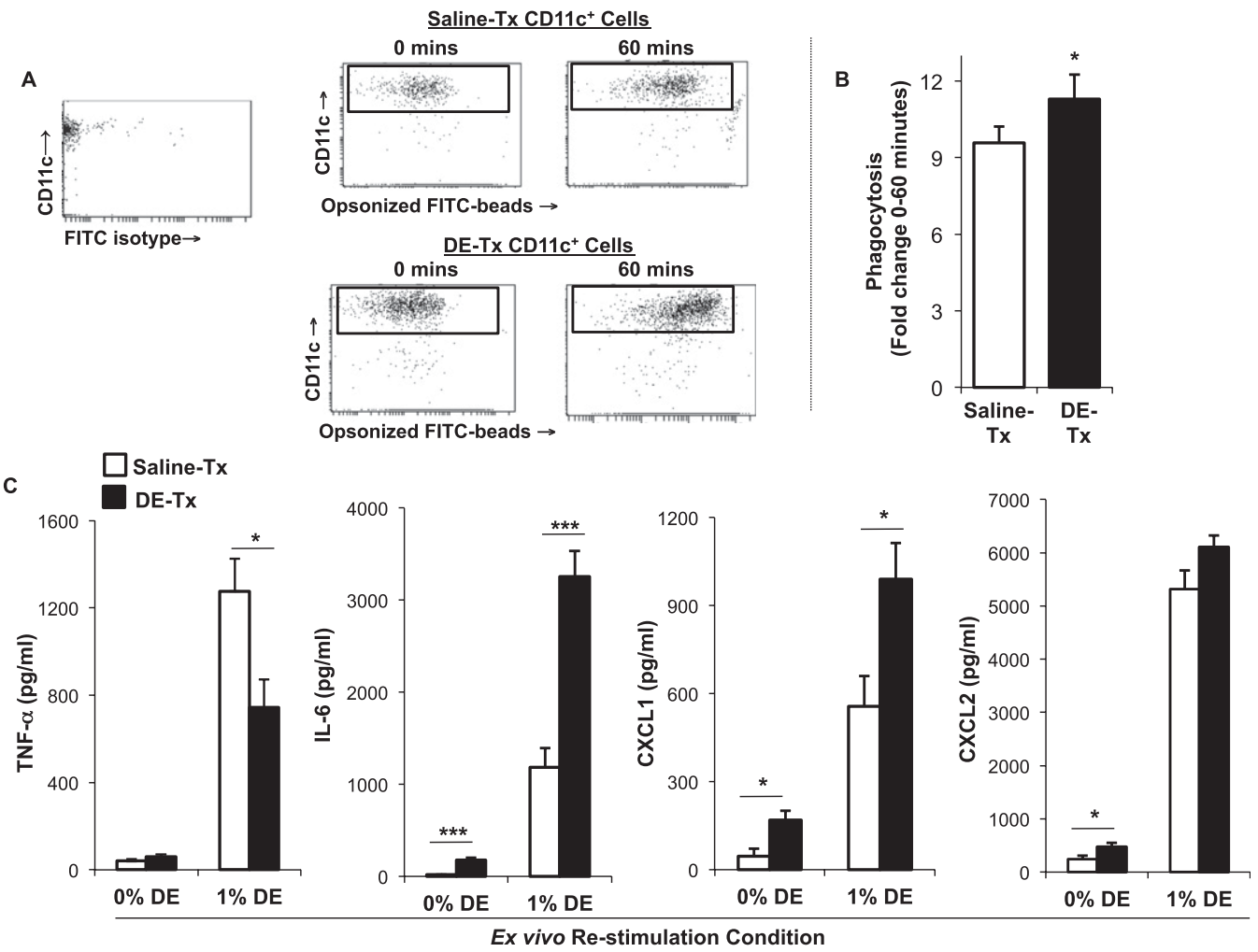

Figure 2. DE treatment increases phagocytosis and cytokine production by $\mathrm{CD}_{11 \mathrm{c}^{+}}$lung cells. C57BL/6 mice were repetitively exposed to $D E$ or saline for 3 weeks, and lungassociated cells were exposed ex vivo to FITC-labeled Saccharomyces cerevisiae zymosan-A bioparticles at 0 and 60 minutes to determine the phagocytic ability of gated $\mathrm{CD}_{11 \mathrm{c}^{+}}$lung macrophages. (A) A representative dot plot depicts particle uptake in gated CD11 $\mathrm{C}^{+} \mathrm{Ly}-6 \mathrm{G}^{-}$macrophages from DE-treated mice and saline control-treated mice as a rightward shift in fluorescence. (B) The phagocytic ability of macrophages is shown as fold change in mean MFI ( \pm SEM) of the proportion of cells in the zymosanexposed gated population at 60 minutes, compared with cells exposed for 0 minutes from $\mathrm{DE}$ and saline control mice ( $n=6$ mice/ group). (C) $\mathrm{CD} 11 \mathrm{c}^{+}$macrophages isolated by FACS from DE-treated mice and saline-exposed mice were restimulated ex vivo with DE (1\%) or saline $(0 \% \mathrm{DE})$ for 24 hours, and cytokine/chemokine concentrations were measured in cell-free supernatant by ELISA. Results represent the mean \pm SEM ( $n=6-9$ mice/group), with statistical significance between saline-and DE-treated denoted by asterisks $\left({ }^{*} P<0.05\right.$ and $\left.{ }^{* \star *} P<0.001\right)$.

CL-LIP + DE and SL-LIP + DE treatment groups (Figures 7A and $7 \mathrm{~B})$. Semiquantitative analysis of these DE-induced histopathologic changes were assessed, using an established lung pathology scoring system (inflammatory score range of 0-3) (6). Significant increases were observed in the inflammatory scores for all parameters assessed in the CL-LIP + DE treatment group
A

Saline-Tx

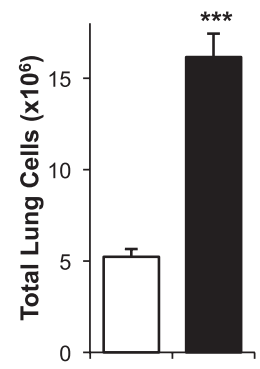

B
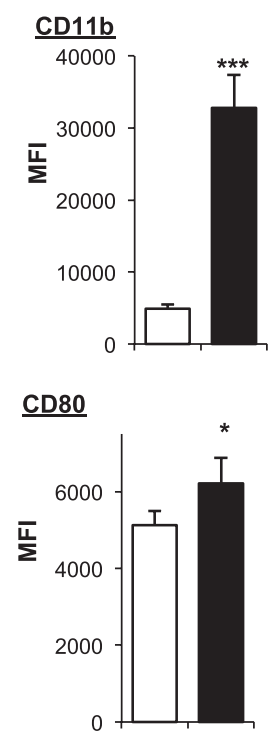

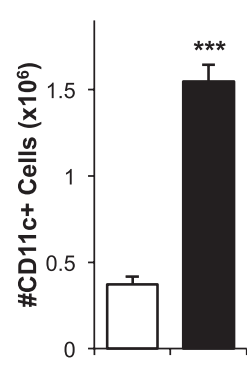

IA-b
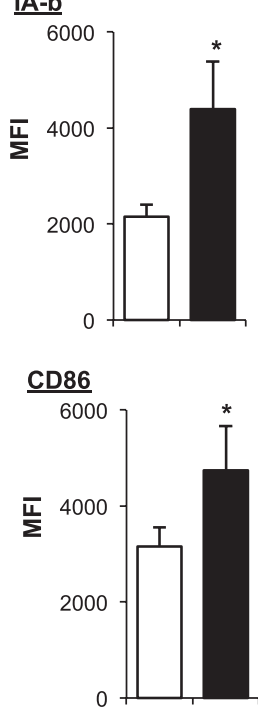

C

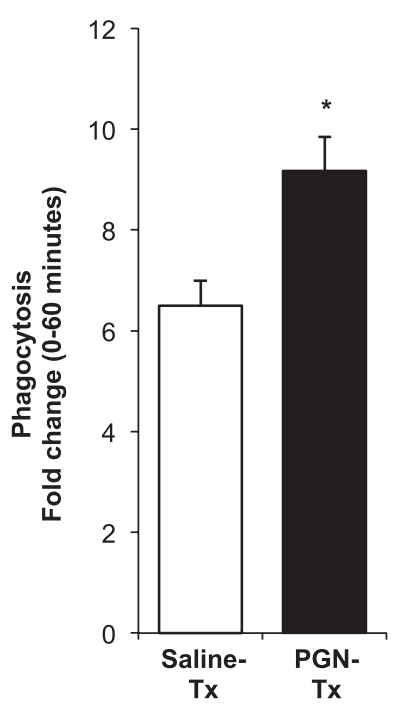

Figure 3. Repetitive intranasal challenge with peptidoglycan (PGN) increases activated $\mathrm{CD}_{11 \mathrm{c}^{+}}$lung macrophages. C57BL/6 mice were repetitively exposed to PGN $(100 \mu \mathrm{g})$ or saline for 3 weeks, and lung-associated cells were enumerated and stained for FACS. (A) Results represent the means \pm SEM $(n=6$ mice/group) of total lung cells and $\mathrm{CD}_{11 \mathrm{c}^{+}}$lung macrophages. (B) The mean fluorescence intensity (MFI) of surface marker expression on gated $\mathrm{CD}_{11 \mathrm{c}^{+}}$cells is shown. Next, lungassociated cells were exposed ex vivo to FITC-labeled Saccharomyces cerevisiae zymosan-A bioparticles at 0 and 60 minutes, to determine the phagocytic ability of gated $\mathrm{CD}_{11 \mathrm{c}^{+}}$lung macrophages. (C) Results represent fold changes in MFI (proportion of cells in the gated population at $60 \mathrm{~min}$, compared with cells exposed for $0 \mathrm{~min}$ ), expressed as means \pm SEM $(n=$ 6 mice/group). Statistical significance is denoted by asterisks ( ${ }^{\star} P<0.05$ and $\left.{ }^{* * * P}<0.001\right)$. 

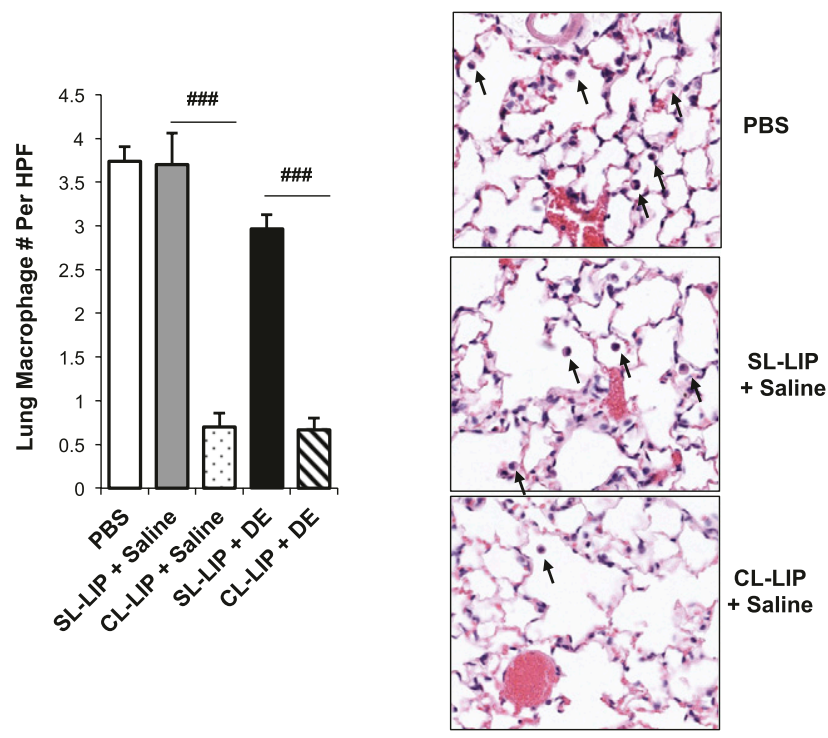

compared with the SL-LIP + DE treatment group. In particular, the CL-LIP + DE treatment group demonstrated larger and increased numbers of cellular aggregates that were distributed diffusely through the lung. Collectively, these studies demonstrate that lung macrophages play a key role in controlling repetitive DE-induced lung inflammatory responses.

\section{DISCUSSION}

Here we report that repetitive exposure to organic DE elicited the influx of activated lung $\mathrm{CD} 11 \mathrm{c}^{+} / \mathrm{CD} 11 \mathrm{~b}^{+}$macrophages, as
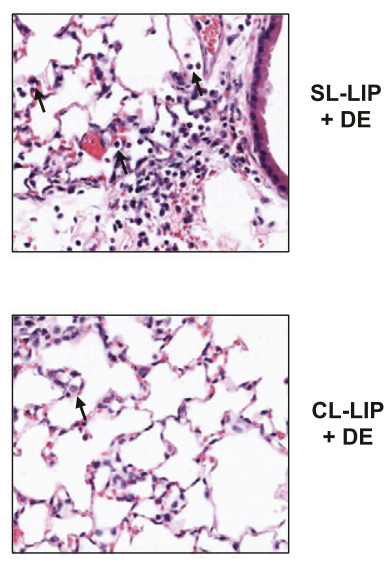

Figure 4. Clodronate-encapsulated liposome treatment reduces lung alveolar macrophages. C57BL/6 mice were treated with clodronate liposomes (CL-LIP) and saline liposomes (SL-LIP), and exposed to saline or DE 48 hours later. Lung sections of all four mice per group were stained with hematoxylin and eosin, and lung macrophages in peripheral and central lung fields (10 total fields/section) were counted and averaged per individual mouse. (A) Results represent the means \pm SEM of lung macrophage numbers per high-power field (HPF) in each group. (B) A representative 4- to $5-\mu \mathrm{m}$ thick section from each group is shown at $\times 40$ magnification. Arrows indicate alveolar macrophages. Statistical significance is denoted by hatch marks $\left({ }^{\# \# \# P<0.001)}\right.$ between SL-LIP-treated and CL-LIP DE-treated mice.

marked by enhanced costimulatory molecule expression, phagocytic ability, and selective cytokine/chemokine responsiveness. Exposure to PGN, a major bacterial cell-wall component in porcine and other large animal confinement facilities $(29,30)$, also resulted in an influx of activated $\mathrm{CD} 11 \mathrm{c}^{+} / \mathrm{CD}_{11} \mathrm{~b}^{+}$macrophages. This corroborates previous studies from our group demonstrating a critical role for PGN as a bioactive component for eliciting lung inflammation. This work advances our understanding of the role that the lung macrophage plays in controlling repetitive DE-induced airway inflammatory responses, because airway and lung parenchymal inflammation

A

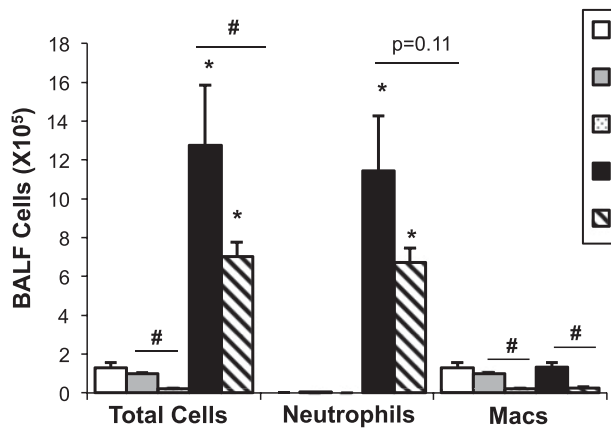

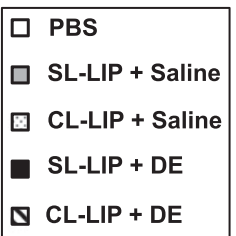

B

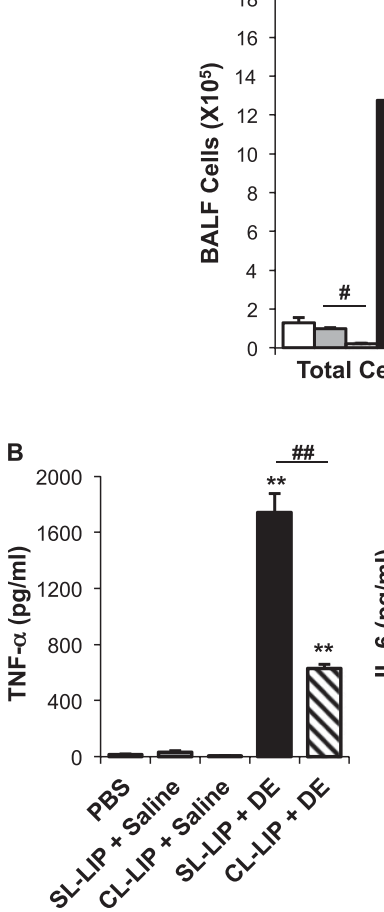

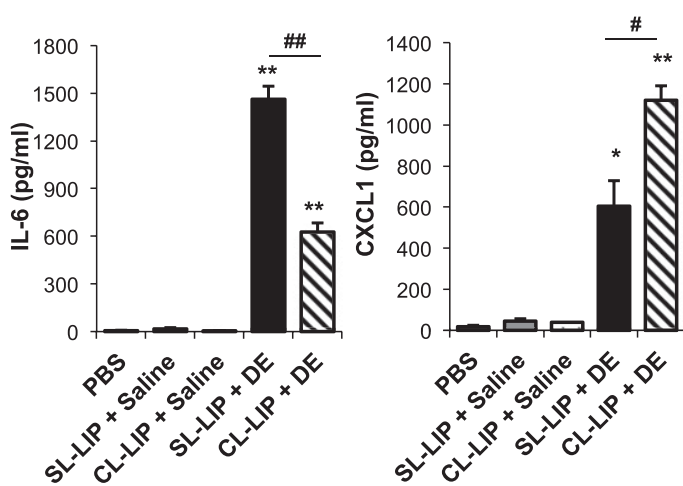

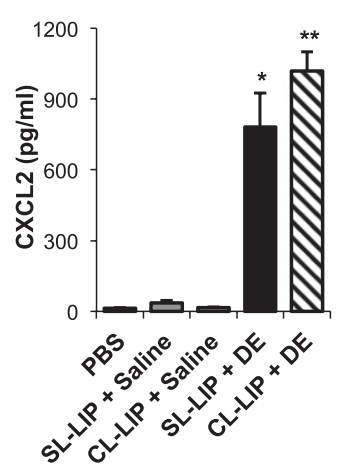

Figure 5. Alveolar macrophages (Macs) are important in mediating acute airway inflammatory response to DE. C57BL/6 mice were treated with clodronate liposomes (CL-LIP) or saline liposomes (SL-LIP) 2 days before a one-time DE challenge. Mice were subsequently challenged with DE or saline, and bronchoalveolar lavage fluid (BALF) was collected 5 hours after exposure. ( $A$ ) Results represent the means \pm SEM of total cells and cell differentials. $(B)$ Results represent mean \pm SEM of cytokine/chemokine concentrations quantitated in cell-free BALF. PBS-only controls are also shown ( $n=4$ mice per group). Statistical significance is denoted by asterisks ( ${ }^{*} P<0.05$ and $\left.{ }^{*} P<0.01\right)$ between respective saline-treated and DEtreated groups. ${ }^{\#} P<0.05$ and ${ }^{\# \#} P<0.01$ indicate statistical significance between SL-LIP-treated and CL-LIP DE-treated mice. 
A

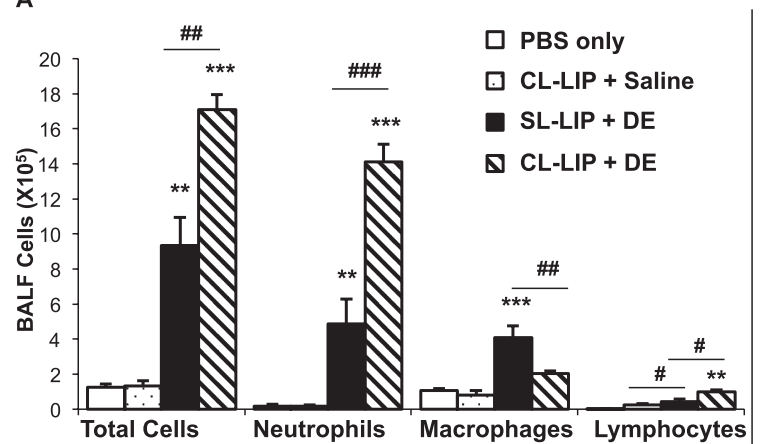

B

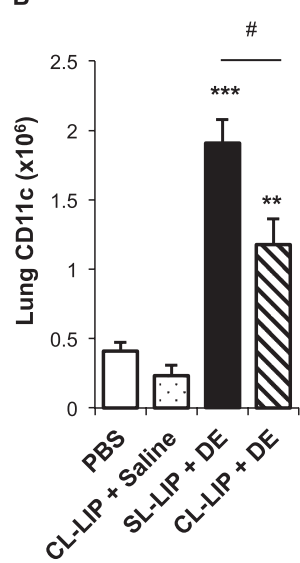

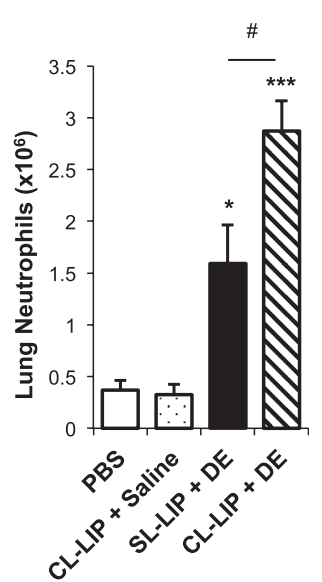

Figure 6. Repetitive DE-induced neutrophilic influx is increased when lung macrophages are depleted. C57BL/6 mice were treated with clodronate liposomes (CL-LIP) or saline liposomes (SL-LIP) beginning 2 days before the first DE challenge, and then every 3 to 4 days during the daily 3-week repetitive $D E$ or saline exposure. (A) Results represent the means $\pm \operatorname{SEM}(n=4$ mice/ group) of the total cells and cell differentials recovered from the BALF of mice. Next, lungassociated cells were collected

from mice, and total cells were enumerated and stained by FACS. (B) Results represent means \pm SEM ( $n=4$ mice/group) of CD11 ${ }^{+}$lung macrophages and neutrophils (percentage of cell type $\times$ total lung cell count). Statistical significance is denoted by asterisks $\left({ }^{*} P<0.05,{ }^{*} P<0.01\right.$, and $\left.{ }^{* * *} P<0.001\right)$ between respective saline-treated and DE-treated groups. Hatch marks ( ${ }^{\#} P<0.05,{ }^{\# \#} P<0.01$, and ${ }^{\# \# \# P<0.001)}$ indicate statistical differences between SL-LIP + DE-treated and CL-LIP + DE-treated mice.

marked by neutrophil influx became worse after macrophage depletion by clodronate liposomes. These experiments establish that DE-activated $\mathrm{CD} 11 \mathrm{c}^{+} / \mathrm{CD} 11 \mathrm{~b}^{+}$macrophages are, in part, responsible for down-regulating the chronic inflammatory lung response to organic dust exposures.

The chronic inflammatory adaptation response to organic dust environments is well-recognized (3), but the important underlying cellular mechanisms have not been clear. Alveolar macrophages are key innate immune cells that are rapidly activated and orchestrate immune responses after exposure to inhaled environmental toxins, such as organic dust, bacterial products, particulate air pollution, and ozone $(9,13,31)$. Macrophages can produce inflammatory mediators and regulate and resolve chronic inflammatory responses by clearing bacteria, debris, and apoptotic cells (32). Activated CD11c ${ }^{+}$lung macrophages are a common feature of inflammatory responses after exposure to various viral or bacterial pathogens $(12,16,20,33$, 34). Our findings support that repetitive exposure to DE induces an analogous activated $\mathrm{CD}_{11 \mathrm{c}^{+}}$macrophage phenotype, with findings of high $\mathrm{CD}_{11} \mathrm{~b}^{+}$and costimulatory molecule expression and phagocytic ability (Figures 1 and 2). DE treatment did not augment MHC Class II expression, which is a feature that was also observed in other infectious models (22). This may represent a regulatory signal or differences in the recycling of the MHC Class II complex (35). Although lung infections are not a common characteristic of lung disease in farmers, animal facilities are associated with a large diversity of microbial agents, and particularly Gram-positive bacteria ( $>$ 80-95\%) $(29,30)$. Indeed, repetitive exposure to PGN, a major cellwall component of Gram-positive and, to a lesser degree, Gramnegative bacteria, also resulted in similar increases of CD11c ${ }^{+}$ macrophage activation.

We found evidence of a "priming effect," as revealed by enhanced IL- 6 and CXCL1 after the stimulation of CD11c ${ }^{+}$cells from DE-challenged mice (Figure 2C). Furthermore, the basal release of IL-6, CXCL1, and CXCL2 was significantly increased in CD11 ${ }^{+}$cells isolated from DE-treated mice. This would indicate cellular responsiveness triggered by $\mathrm{DE}$ in vivo, because no additional stimulus was used. However, this "primed" or activated status was not global because $\mathrm{TNF}-\alpha$ responsiveness was dampened, consistent with the so-called tolerant response/ adapted response $(1,36)$. However, a hyperresponsiveness in cytokine release with ex vivo, endotoxin-stimulated whole blood from farmers compared with healthy control subjects has been reported $(37,38)$.
A

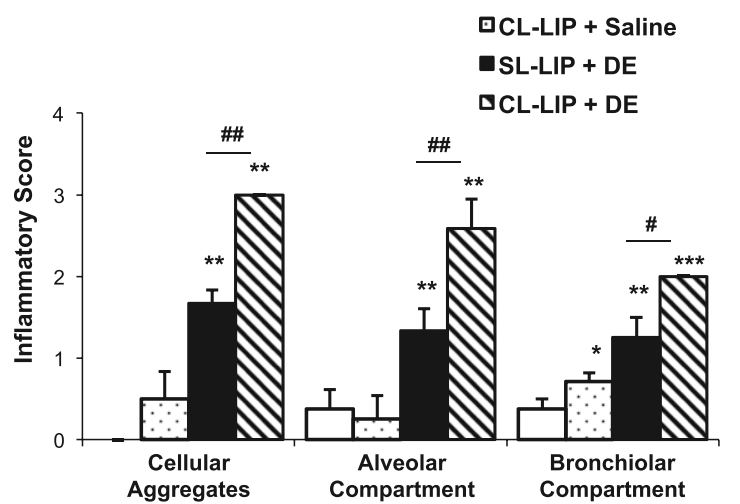

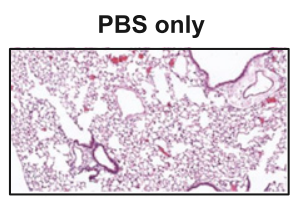

SL-LIP + DE

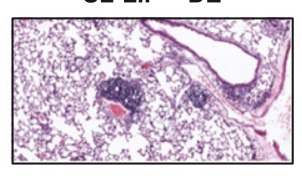

CL-LIP + Saline

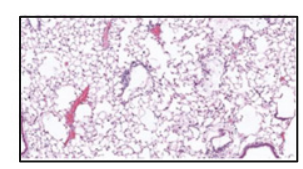

CL-LIP + DE

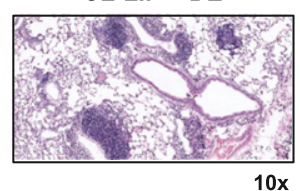

Figure 7. Lung macrophages are important in mediating repetitive $\mathrm{DE}$-induced lung inflammation. C57BL/6 mice were treated with clodronate liposomes (CL-LIP) or saline liposomes (SL-LIP) beginning 2 days before the first $\mathrm{DE}$ challenge, and then every 3 to 4 days during the daily 3 -week repetitive DE or saline exposure. (A) Semiquantitative inflammatory scores (means \pm SEM; $n=4$ mice per group) of the degree and distribution of cellular aggregates, and of alveolar and bronchiolar lung inflammation, are shown. PBS-only control scores are also shown. (B) A representative 4- to 5- $\mu \mathrm{m}$-thick, hematoxylinand-eosin-stained section of one of four mice per treatment group is shown at $\times 10$ magnification. All lung specimens were inflated to $10 \mathrm{~cm} \mathrm{H}_{2} \mathrm{O}$ pressure during fixation to avoid atelectasis artifacts. Statistical significance is denoted by asterisks $\left({ }^{*} P<0.05,{ }^{*} P<0.01\right.$, and $\left.{ }^{* * *} P<0.001\right)$ between respective saline-treated and DE-treated groups. ${ }^{\#} P<0.05$ and ${ }^{\# \#} P<0.01$ indicate statistical difference between SL-LIP + DE-treated and CL-LIP + DE-treated mice. 
The finding that CD11b expression was dramatically increased in DE-exposed CD11 ${ }^{+}$cells is also important. Although CD11b is well recognized for its role in leukocyte adhesion and activation, phagocytosis, and transmigration (39), CD11b expression on mononuclear phagocytes within the respiratory tract has been correlated with airway neutrophilia $(9,40)$, and the correlation with airway neutrophilia is supported by our studies. Activated macrophages may contribute to DE-induced airway neutrophilia. However, CD $11 \mathrm{c}^{+} /$ $\mathrm{CD}_{11} \mathrm{~b}^{+}$macrophages are more likely responding to the inflammatory insult in an attempt to control and resolve disease. This possibility is supported by our demonstration that without an adequate lung macrophage population, enhanced inflammatory consequences follow repetitive DE exposure (Figures 6 and 7). Previous work established that the mononuclear cellular aggregates induced by repetitive organic dust exposure comprise an admixture of $\mathrm{T}$ and $\mathrm{B}$ lymphocytes and phagocytes (6). Furthermore, DE-induced cellular aggregates consist of live cells $(>98.5 \%)$, as opposed to clumps of apoptotic cells based on the common method for detecting DNA fragmentation, terminal deoxynucleotidyl transferase dUTP nick end labeling (TUNEL) staining of tissue sections (data not shown).

In acute DE exposure studies within the setting of lung macrophage depletion, findings suggest that the alveolar macrophage is likely a major source for TNF- $\alpha$ and IL-6 production after acute DE exposure (Figure 5). In contrast, the macrophage does not appear to be an important source of neutrophil chemoattractants during DE-induced airway inflammation (Figure 5). This implies that other cell types, such as airway epithelium, may be important sources of DE-induced neutrophil chemoattractants. Furthermore, TNF- $\alpha$ expression was demonstrated in airway epithelial cells in all groups by an immunohistochemical staining procedure (Figure E3). Isolated airway epithelial cells produce substantial amounts of neutrophil chemoattractants after organic dust exposures $(25,41,42)$. Without macrophages to phagocytize and remove the organic dust burden effectively, the airway epithelium may hyperrespond to an increased DE load.

Trends toward a reduction in DE-induced acute neutrophil counts were observed in the setting of macrophage depletion, despite the lack of reduction in murine neutrophil chemoattractants. With repetitive DE exposures, an adaptation-like response occurs, marked by decreased CXCL1 and CXCL2 expression, although neutrophil influx remains elevated $(6,7)$. Likewise, in our study, the cytokine/chemokine response diminished and did not differ between groups (data not shown), yet neutrophil influx remained elevated after repetitive DE exposures, and this elevation was further enhanced when macrophages were deleted (Figures 6 and 7). These observations highlight that the control and regulation of neutrophil recruitment after lung injury are not limited to chemokines, but may include a number of complex factors and networks (e.g., integrins, selectins, proteases, and reactive oxygen species) (43). Moreover, extracts of organic dusts from agricultural environments exhibit direct chemotactic activity in vitro, and this response has been shown to be independent of endotoxin $(44,45)$. This response may also be driven by $N$-formyl-methionyl peptides, motifs of microbial proteins, which can also trigger neutrophil recruitment via the formylated peptide receptor (46). Future lines of study should explore other mechanisms of neutrophil influx, and investigate and characterize subpopulations of DE-induced lung macrophages (e.g., M1, M2a, M2b, and M2c) (47).

Although we found no evidence of distress or mortality, mice receiving repetitive clodronate liposome treatment, regardless of subsequent DE or saline exposure, failed to exhibit equivalent weight gain, compared with their respective control mice. Although the reason for this observation is not entirely clear, repeated clodronate liposome treatment (i.e., 2-3 repeated challenges) was reported to cause subtle immunologic changes $(18,48)$. By extension, the host may elicit a compensatory mechanism to respond to the reduction in macrophages. Thus, we cannot completely eliminate the possibility of a nonspecific clodronate liposome effect in our repetitive delivery studies.

In conclusion, inhalation exposure to organic DE from swine confinement facilities induces an influx of activated $\mathrm{CD} 11 \mathrm{c}^{+} / \mathrm{CD} 11 \mathrm{~b}^{+}$macrophages in the lung. Moreover, PGN, a component of organic dust, elicited a similar lung response, suggesting that PGN may be an important player in complex organic dust-induced pathogenic lung inflammation. Our findings establish that lung macrophages are key in the acute response to DE, and furthermore, lung macrophages are critical in down-regulating inflammatory responses after prolonged, repetitive DE exposures. This information may be important because potential therapies such as macrolides and vitamin $\mathrm{D}$ were shown to enhance macrophage phagocytic ability or autophagy (49-52). Future studies are warranted to investigate whether promoting macrophage function might ultimately lead to novel approaches to reduce chronic organic dust-induced airway inflammatory consequences in exposed agricultural workers.

Author disclosures are available with the text of this article at www.atsjournals.org.

Acknowledgments: The authors thank Megan Michalak, Victoria Smith, and Charles Kuzinski, Ph.D., of the Cell Analysis Facility at the University of Nebraska Medical Center for assistance with flow cytometric measurements, Greg Dooley, Ph.D., for assistance with the mass spectrometry analysis of dust samples, and Geoffrey Talmon, M.D., David Muirhead, and David Wert of the Tissue Science Facility at the University of Nebraska Medical Center and Thomas Jerrells, Ph.D., for assistance with digital microscopy images prepared for the manuscript. The authors also thank Lisa Chudomelka for assistance with preparation of the manuscript.

\section{References}

1. Von Essen S, Romberger D. The respiratory inflammatory response to the swine confinement building environment: the adaptation to respiratory exposures in the chronically exposed worker. J Agric Saf Health 2003;9:185-196.

2. Eduard W, Pearce N, Douwes J. Chronic bronchitis, COPD, and lung function in farmers: the role of biological agents. Chest 2009;136: $716-725$.

3. Sundblad BM, von Scheele I, Palmberg L, Olsson M, Larsson K. Repeated exposure to organic material alters inflammatory and physiological airway responses. Eur Respir J 2009;34:80-88.

4. Palmberg L, Larssson BM, Malmberg P, Larsson K. Airway responses of healthy farmers and nonfarmers to exposure in a swine confinement building. Scand J Work Environ Health 2002;28:256-263.

5. Schwartz DA, Donham KJ, Olenchock SA, Popendorf WJ, Van Fossen DS, Burmeister LF, Merchant JA. Determinants of longitudinal changes in spirometric function among swine confinement operators and farmers. Am J Respir Crit Care Med 1995;151:47-53.

6. Poole JA, Wyatt TA, Oldenburg PJ, Elliott MK, West WW, Sisson JH, Von Essen SG, Romberger DJ. Intranasal organic dust exposureinduced airway adaptation response marked by persistent lung inflammation and pathology in mice. Am J Physiol Lung Cell Mol Physiol 2009;296:L1085-L1095.

7. Charavaryamath C, Janardhan KS, Townsend HG, Willson P, Singh B. Multiple exposures to swine barn air induce lung inflammation and airway hyper-responsiveness. Respir Res 2005;6:50.

8. Arjomandi M, Witten A, Abbritti E, Reintjes K, Schmidlin I, Zhai W, Solomon C, Balmes J. Repeated exposure to ozone increases alveolar macrophage recruitment into asthmatic airways. Am J Respir Crit Care Med 2005;172:427-432.

9. Alexis NE, Lay JC, Zeman K, Bennett WE, Peden DB, Soukup JM, Devlin RB, Becker S. Biological material on inhaled coarse fraction particulate matter activates airway phagocytes in vivo in healthy volunteers. J Allergy Clin Immunol 2006;117:1396-1403. 
10. Lay JC, Alexis NE, Kleeberger SR, Roubey RA, Harris BD, Bromberg PA, Hazucha MG, Devlin RB, Peden DB. Ozone enhances markers of innate immunity and antigen presentation on airway monocytes in healthy individuals. J Allergy Clin Immunol 2007;120:719-722.

11. Fels AO, Cohn ZA. The alveolar macrophage. J Appl Physiol 1986;60: 353-369.

12. Thepen T, Kraal G, Holt PG. The role of alveolar macrophages in regulation of lung inflammation. Ann N Y Acad Sci 1994;725:200-206.

13. Poole JA, Alexis NE, Parks C, MacInnes AK, Gentry-Nielsen MJ, Fey PD, Larsson L, Allen-Gipson D, Von Essen SG, Romberger DJ. Repetitive organic dust exposure in vitro impairs macrophage differentiation and function. J Allergy Clin Immunol 2008;122:375-382.

14. Martin TR, Frevert CW. Innate immunity in the lungs. Proc Am Thorac Soc 2005;2:403-411.

15. Gonzalez-Juarrero M, Shim TS, Kipnis A, Junqueira-Kipnis AP, Orme IM. Dynamics of macrophage cell populations during murine pulmonary tuberculosis. J Immunol 2003;171:3128-3135.

16. Guth AM, Janssen WJ, Bosio CM, Crouch EC, Henson PM, Dow SW Lung environment determines unique phenotype of alveolar macrophages. Am J Physiol Lung Cell Mol Physiol 2009;296:L936-946.

17. Lai JF, Zindl CL, Duffy LB, Atkinson TP, Jung YW, van Rooijen N, Waites KB, Krause DC, Chaplin DD. Critical role of macrophages and their activation via MyD88-NFkappaB signaling in lung innate immunity to mycoplasma pneumoniae. PLoS ONE 2010;5:e14417.

18. Tate MD, Pickett DL, van Rooijen N, Brooks AG, Reading PC. Critical role of airway macrophages in modulating disease severity during influenza virus infection of mice. J Virol 2010;84:7569-7580.

19. Landsman L, Varol C, Jung S. Distinct differentiation potential of blood monocyte subsets in the lung. J Immunol 2007;178:2000-2007.

20. Matthews KE, Karabeg A, Roberts JM, Saeland S, Dekan G, Epstein MM, Ronchese F. Long-term deposition of inhaled antigen in lung resident

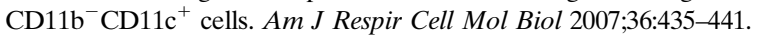

21. Pedersen B, Iversen M, Bundgaard Larsen B, Dahl R. Pig farmers have signs of bronchial inflammation and increased numbers of lymphocytes and neutrophils in BAL fluid. Eur Respir $J$ 1996;9:524-530.

22. Archambaud C, Salcedo SP, Lelouard H, Devilard E, de Bovis B, Van Rooijen N, Gorvel JP, Malissen B. Contrasting roles of macrophages and dendritic cells in controlling initial pulmonary Brucella infection. Eur J Immunol 2010;40:3458-3471.

23. Narasaraju T, Yang E, Samy RP, Ng HH, Poh WP, Liew AA, Phoon MC, Van Rooijen N, Chow VT. Excessive neutrophils and neutrophil extracellular traps contribute to acute lung injury of influenza pneumonitis. Am J Pathol 2011;179:199-210.

24. Poole JA, Thiele GM, Alexis NE, Burrell AM, Parks C, Romberger DJ. Organic dust exposure alters monocyte-derived dendritic cell differentiation and maturation. Am J Physiol Lung Cell Mol Physiol 2009; 296:L767-L776.

25. Romberger DJ, Bodlak V, Von Essen SG, Mathisen T, Wyatt TA. Hog barn dust extract stimulates IL-8 and IL-6 release in human bronchia epithelial cells via PKC activation. J Appl Physiol 2002;93:289-296.

26. Poole JA, Wyatt TA, Kielian T, Oldenburg P, Gleason AM, Bauer A, Sisson JH, Romberger DJ. Toll-like receptor 2 regulates organic dust-induced airway inflammation. Am J Respir Cell Mol Biol 2011;45:711-719.

27. Poole JA, Kielian T, Wyatt TA, Gleason AM, Stone J, Palm K, et al. Organic dust augments nucleotide-binding oligomerization domain (NOD2) expression via an NF-\{kappa\}B pathway to negatively regulate inflammatory responses. Am J Physiol Lung Cell Mol Physiol 2011;301:L296-L306.

28. Thepen T, Van Rooijen N, Kraal G. Alveolar macrophage elimination in vivo is associated with an increase in pulmonary immune response in mice. J Exp Med 1989;170:499-509.

29. Nehme B, Letourneau V, Forster RJ, Veillette M, Duchaine C. Cultureindependent approach of the bacterial bioaerosol diversity in the standard swine confinement buildings, and assessment of the seasonal effect. Environ Microbiol 2008;10:665-675.

30. Poole JA, Dooley GP, Saito R, Burrell AM, Bailey KL, Romberger DJ, Mehaffy J, Reynolds SJ. Muramic acid, endotoxin, 3-hydroxy fatty acids, and ergosterol content explain monocyte and epithelial cell inflammatory responses to agricultural dusts. $J$ Toxicol Environ Health A 2010;73:684-700.

31. Borish LC, Steinke JW. 2. cytokines and chemokines. J Allergy Clin Immunol 2003;111: S460-S475.
32. Marriott HM, Dockrell DH. The role of the macrophage in lung disease mediated by bacteria. Exp Lung Res 2007;33:493-505.

33. Osterholzer JJ, Chen GH, Olszewski MA, Curtis JL, Huffnagle GB, Toews GB. Accumulation of $\mathrm{CD}_{11} \mathrm{~b}^{+}$lung dendritic cells in response to fungal infection results from the CCR2-mediated recruitment and differentiation of Ly-6Chigh monocytes. J Immunol 2009;183:80448053.

34. Fei M, Bhatia S, Oriss TB, Yarlagadda M, Khare A, Akira S, Saijo S, Iwakura Y, Fallert Junecko BA, Reinhart TA, et al. TNF-alpha from inflammatory dendritic cells (DCs) regulates lung IL-17A/IL-5 levels and neutrophilia versus eosinophilia during persistent fungal infection. Proc Natl Acad Sci USA 2011;108:5360-5365.

35. von Delwig A, Musson JA, Shim HK, Lee JJ, Walker N, Harding CV, Williamson ED, Robinson JH. Distribution of productive antigenprocessing activity for MHC Class II presentation in macrophages. Scand J Immunol 2005;62:243-250.

36. Hoffmann HJ, Iversen M, Sigsgaard T, Omland O, Takai H, BonefeldJorgensen E, Seedorf J, Dahl R. A single exposure to organic dust of non-naive non-exposed volunteers induces long-lasting symptoms of endotoxin tolerance. Int Arch Allergy Immunol 2005;138:121-126.

37. Lambert GP, Spurzem JR, Romberger DJ, Wyatt TA, Lyden E, Stromquist AM, Merchant JA, Von Essen S. Tumor necrosis factor-alpha hyperresponsiveness to endotoxin in whole blood is associated with chronic bronchitis in farmers. J Agromed 2005;10:39-44.

38. Dosman JA, Fukushima Y, Senthilselvan A, Kirychuk SP, Lawson JA, Pahwa P, Cormier Y, Hurst T, Barber EM, Rhodes CS. Respiratory response to endotoxin and dust predicts evidence of inflammatory response in volunteers in a swine barn. Am J Ind Med 2006;49:761-766.

39. Ehlers MR. CR3: a general purpose adhesion-recognition receptor essential for innate immunity. Microbes Infect 2000;2:289-294.

40. Alexis NE, Eldridge MW, Peden DB. Effect of inhaled endotoxin on airway and circulating inflammatory cell phagocytosis and CD11b expression in atopic asthmatic subjects. J Allergy Clin Immunol 2003; 112:353-361.

41. Wyatt TA, Slager RE, Heires AJ, Devasure JM, Vonessen SG, Poole JA, Romberger DJ. Sequential activation of protein kinase $\mathrm{C}$ isoforms by organic dust is mediated by tumor necrosis factor. Am J Respir Cell Mol Biol 2010;42:706-715.

42. Wyatt TA, Slager RE, Devasure J, Auvermann BW, Mulhern ML, Von Essen S, Mathisen T, Floreani AA, Romberger DJ. Feedlot dust stimulation of interleukin- 6 and -8 requires protein kinase $\mathrm{C}\{$ varepsilon\} in human bronchial epithelial cells. Am J Physiol Lung Cell Mol Physiol 2007;293:L1163-L1170.

43. Grommes J, Soehnlein O. Contribution of neutrophils to acute lung injury. Mol Med 2011;17:293-307.

44. Buck MG, Schachter EN, Fick RB, Merrill WW, Cooper JA, Jr, Keirns JJ, Oliver J, Wall JH. Biologic activity of purified cotton bract extracts in man and guinea pig. Environ Health Perspect 1986;66:37-44.

45. Von Essen SG, O'Neill DP, Robbins RA, Rennard SI. Neutrophil chemotaxis to extracts of grain plant components. Am J Ind Med 1994:25:85-88.

46. Dalpiaz A, Spisani S, Biondi C, Fabbri E, Nalli M, Ferretti ME. Studies on human neutrophil biological functions by means of formyl-peptide receptor agonists and antagonists. Curr Drug Targets Immune Endocr Metabol Disord 2003;3:33-42.

47. Benoit M, Desnues B, Mege JL. Macrophage polarization in bacterial infections. J Immunol 2008;181:3733-3739.

48. Zhao J, Zhao J, Van Rooijen N, Perlman S. Evasion by stealth: inefficient immune activation underlies poor $\mathrm{T}$ cell response and severe disease in SARS-CoV-infected mice. PLoS Pathog 2009;5:e1000636.

49. Hodge S, Hodge G, Jersmann H, Matthews G, Ahern J, Holmes M, Reynolds PN. Azithromycin improves macrophage phagocytic function and expression of mannose receptor in chronic obstructive pulmonary disease. Am J Respir Crit Care Med 2008;178:139-148.

50. Hodge S, Hodge G, Brozyna S, Jersmann H, Holmes M, Reynolds PN. Azithromycin increases phagocytosis of apoptotic bronchial epithelial cells by alveolar macrophages. Eur Respir J 2006;28:486-495.

51. Wu S, Sun J. Vitamin D, vitamin D receptor, and macroautophagy in inflammation and infection. Discov Med 2011;11:325-335.

52. Hoyer-Hansen M, Nordbrandt SP, Jaattela M. Autophagy as a basis for the health-promoting effects of vitamin D. Trends Mol Med 2010;16: 295-302. 